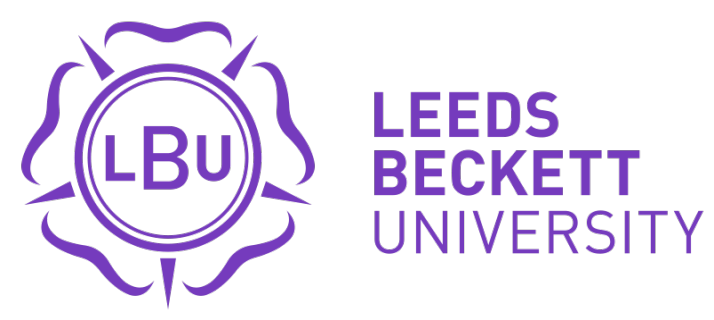

Citation:

Julian, R (2016) Is it for donors or locals? The relationship between stakeholder interests and demonstrating results in International Development. International Journal of Managing Projects in Business, 9 (3). ISSN 1753-8378 DOI: https://doi.org/10.1108/IJMPB-09-2015-0091

Link to Leeds Beckett Repository record:

https://eprints.leedsbeckett.ac.uk/id/eprint/2522/

Document Version:

Article (Accepted Version)

The aim of the Leeds Beckett Repository is to provide open access to our research, as required by funder policies and permitted by publishers and copyright law.

The Leeds Beckett repository holds a wide range of publications, each of which has been checked for copyright and the relevant embargo period has been applied by the Research Services team.

We operate on a standard take-down policy. If you are the author or publisher of an output and you would like it removed from the repository, please contact us and we will investigate on a case-by-case basis.

Each thesis in the repository has been cleared where necessary by the author for third party copyright. If you would like a thesis to be removed from the repository or believe there is an issue with copyright, please contact us on openaccess@leedsbeckett.ac.uk and we will investigate on a case-by-case basis. 


\title{
Is it for donors or locals? The relationship between stakeholder interests and demonstrating results in International Development.
}

\author{
Abstract \\ Purpose
}

Many development interventions fail to report results that are important to local people (intended beneficiaries of the intervention) but not of strategic importance to the donors funding the work. Failure to report unexpected results, or those not linked to strategic goals, contributes to an overly negative view from external evaluations by donors and agencies. The causes of the mismatch between actual and demonstrated results failure were studied through stakeholder interests.

\section{Design/methodology/approach}

Nine project and programme managers of similar but unrelated projects were interviewed. From the interviews, previous studies and project publications, the challenges posed by differing interests and different perceptions in reporting stakeholder activities, outputs and outcomes, were identified. The complex environment of many development interventions was analysed and the work was contextualized with a peacebuilding project in Sri Lanka, which the author has previously studied. A stakeholder role and perception analysis was used to map the challenges at four times in the project cycle, producing a dynamic stakeholder analysis.

\section{Findings}

The failure to fully report intervention results was linked to the changing role of competing stakeholder interests as a project proceeds, the conflicting perceptions of stakeholders, the structural over-simplification of a complex environment, and power differentials that allow donors to misappropriate the role of clients.

\section{Practical implications}

Current practice in designing and evaluating projects needs to improve reporting of beneficiary interests.

\section{Originality/value}

To the author's knowledge there are no prior publications in this area of research (under-reporting of development intervention results); the paper is considered highly original.

\section{Introduction}

Although some work has been done to understand how the success criteria of development interventions are agreed and achieved (Daillo and Thuillier 
2004, Hermano, Lopez-Paredes, Martin-Cruz and Pajares 2013) little work has been published about how the actual results on the ground compare with the reporting of intended results that are based on strategic objectives, as defined in the project planning. For local people, an unexpected result of a project might be beneficial, but this result could be overlooked or even excluded in formal reporting based on the achievement of the funder's planned strategic goals. As a result, the positive impact of the project may be underestimated, or an unintended negative impact ignored. This paper argues that this lack of reporting of local results is not simply due to an evaluation failure to examine impact (as defined in OECD-DAC 2008), but is due to a more fundamental failure to understand what constitutes impact for different stakeholders, influenced by their mental models and competing interests.

Donors who fund international development work are currently increasing their interest in measuring the long-term societal changes (usually called impacts) brought about by interventions, and there is a corresponding increasing expectation that implementers should be able to demonstrate and report the impact of the work that has been funded (International Alert 2009, DFID 2009). This has led to more evaluation of results by large NGOs and funders, and an increase in the annual reporting of "impact". The standard highlysimplified linear model of: inputs, activities, outputs, outcomes and impacts (International Labour Organisation 2010), or the equivalent project cycle approach (European Commission 2002), is often evaluated and presented only from the perspective of the funder and/or planner. Not only are the results on the ground almost certainly very much less linear and likely to include unforeseen impacts (Neufelt 2008, Church and Shouldice 2002), but local partners and local beneficiaries may have their own linear model which foresees different local outcomes and impacts from the same activities and outputs.

The particular focuses of this paper are violence prevention and conflict resolution projects, a subset of International Development projects. The Nonviolent Peaceforce Sri Lanka project (Nonviolent Peaceforce n.d.) provides an example of this type of project and of how the stakeholders are involved. The research draws on published material from organisations involved in violence and conflict resolution, direct experience of the author working in implementing agencies and interviews from nine practitioners who are programme or project managers in violence prevention and conflict resolution. From the analysis of this data, differing stakeholder interests were identified and

Khang and Moe (2008) state that "the real interests of different stakeholders in these projects may be different from the stated objectives in the project document, creating a special dilemma for the implementation." (Khang and Moe 2008:75) Their work proposes that success criteria are dynamic and can change over the entire project life-cycle. This paper extends the dynamic concept from a focus on implementation to all phases of the project cycle, including impact. If only part of the actual 'on the ground' results are included in the formal reporting to the donor (and/or implementer and/or planner), and there are other results only informally known to the local partner and local 
beneficiaries, then an understanding of the full impact will be lost. The evaluation and reporting may meet the stated goals, but will be inadequate in examining the changes to the lives and social context of the intended beneficiaries, and any unintended beneficiaries. Local partners may be satisfied with the results, even though the donor sees little progress towards their strategic goals, or vice versa. There is no shortage of guidance on project management and evaluation (Crawford and Bryce 2003, UNDP 2011), yet, according to practitioners (Julian 2012) there continues to be a gap between what projects actually achieve and the results that are reported and recognised as demonstrated impact. The current evidence indicates there is a low reported success rate for international development projects (Ika 2012), but the research reported here suggests that this lack of apparent success may be due to ignoring or dismissing locally known results, and that there are clear causes for this.

The purpose of this paper is to understand why the many results that happen at the local level in projects are not represented in reports from implementing agencies or donors as the demonstrated results or success. By seeking to understand this issue through the roles and interests of different stakeholders, the paper draws on approaches from project management that give insight into their relationships.

The central issue is explored through an analysis of the differing interests of the key stakeholders (local partners, implementing agency and donors) in both actual and demonstrated results. The process then investigates the reasons for the differing interests of the stakeholders through three frameworks which are; individual mental models, organisational political and cultural systems, and evaluation methodology choice. To fully understand how these factors relate to one another over the project life cycle, the stakeholder interests and frameworks are overlaid onto the project cycle so that the influence and attitudes towards the project can be mapped over time.

\section{Methodology.}

This research is an explorative investigation using qualitative data from both interviews and secondary sources. The research asks how stakeholder interests influence results being understood and accepted in International Development projects over a project cycle.

The empirical data is from interviews with project and programme managers in violence prevention and conflict resolution organisations to investigate the methodologies they use to demonstrate results and the challenges they face. The secondary data is from the published material from the key stakeholder groups to understand the different interests they have in results (DFID 2009, Woodrow 2006, Church and Shouldice 2002, Neufeldt 2008, Julian 2012). The research uses a project in Sri Lanka to contextualise the stakeholder groups and stages of the project cycle. The work has emerged from the author's twenty years of experience in managing the challenge of actual and demonstrated results, working with implementing agency staff in both local and international offices. 
project and programme managers working in the headquarters of international peacebuilding NGO's and donor agencies based in the UK and Brussels.

Seven of the interviewees were employed providing funding or fundraising for projects they ran, and two were consultants to implementing agencies and donors. They were selected from a group of twenty identified in the UK and Brussels because they had responsibility for demonstrating results in projects which had a similar set up to the project example in Sri Lanka. They were interviewed as individuals, although they sometimes referred to organisational policy they recounted their own experiences. In the interviews they were asked about the methods they used for demonstrating results and challenges they faced, their interviews were analysed for thematic conclusions and they are presented anonymously with only a numeric identification (e.g. interviewee 4). Their age is not relevant, but they were all senior professional staff with many years of experience.

Analysis of the interview data revealed the challenge of having different interests in the results. These differing interests were explored through secondary analysis of published materials and the frameworks of 'individual mental models', 'organisational political and cultural systems', and 'evaluation method choice'. These frameworks give us a lens through which we can explain the differing interests, as they appear to work against one another, so that we can discover if the frameworks explain why competing interests exist or how they might have a broader impact on results. The stakeholder analysis data was then mapped onto the project cycle to show the dynamic way in which the frameworks and the analysis of the interest dynamically interrelate.

The secondary data analysis of stakeholder interests is published in Julian (2012) and used in summary in this paper. In this paper the primary research and the results of the data analysis are used to create the dynamic stakeholder analysis over the life of the project cycle showing how the interests inter-relate with the project cycle, with one another and within the framework of four influences on competing interests.

This paper first briefly describes the stakeholder group characteristics and the project life cycle as they relate to the demonstration of results. Stakeholder interests are then assessed through four influences on the competing interests, and finally an analysis of stakeholder group interests is applied to the project life cycle with a focus on results. The conclusions provide some insight on future considerations for understanding the role of competing stakeholder interests in the demonstration and reporting of results.

The specific project studied to contextualise the research is in Sri Lanka, where Nonviolent Peaceforce (Nonviolent Peaceforce 2003-2011 (Schweitzer 2012)) aims to provide a safe environment in which local people could have the capacity to create locally owned peacebuilding initiatives. The project has a structure and stakeholders typical for these types of project, for example a small community in an area experiencing violent conflict is isolated from health, education and other services in the nearest town because of conflict with neighbouring communities. The needs of the community are (i) for access to services locally and (ii) peaceful resolution of conflicts with their neighbours. A large governmental donor is interested in addressing the 
violence in the wider region, and provides some funding to address their needs as part of the larger programme. An implementing agency (such as Nonviolent Peaceforce (NP)) is working in the area and has a track record with the governmental donor, so can secure and manage the funding, including this single isolated village, within a larger portfolio of projects. From the perspective of those in the village the actual results (if the project was successful) would be improved access to services and new communication routes with their neighbours leading to improved safety and security. For reporting and evaluation purposes, the implementing agency need to take actual results from this area and translate them into results that contribute to the strategic aims of the donor. As the donor focus is on improved security and safety, the actual results relating to improved access to services are not included and the reported impact of the funding is not only reduced, but fails to include this locally perceived impact. If external factors at the same time create more tension in the zone, then the security situation might worsen, and excluding the benefits of improved access to services the overall project could appear to be lacking any positive strategic impact, in contrast to the local experience.

This paper uses Khang and Moe's (2008) classification of main stakeholder groups as donors/funding agency, implementing agency and local/target beneficiaries, and also Khang and Moe's (2008) four project stages: concept, planning, implementation and close. Stakeholder interests are demonstrated, based on different mental models, organisational political culture, stakeholder relationships, and how evaluation methodology impacts on how achieved results, and explored across the project cycle. This dynamic relationship between stakeholders, their interests, and the project cycle shows how stakeholders' competing interests, cultures and power inter-relate to produce both a dynamic and complex situation.

A lack of clarity about the nature and identify of the 'project client' role in International Development project management underpins this argument (Daillo and Thuiler 2004). Although a simplistic approach might indicate that the project client is the group for whom the changes are being made (for example the project client in building a house will be the new house owner), this paper suggests that the large governmental donors are also playing a client role. This is shown by their requirements that project objectives must fit their strategic, and sometimes political, aims, and by requiring reporting of results in a from that allows results from different projects or programmes to be amalgamated in a way that will assist in showing how their donor funding has achieved the overall objectives. By imposing a set of expectations on the demonstrated results they are showing client behaviour.

\section{Defining stakeholder groups and their interest in results.}

Freeman (1984) defines stakeholders as 'any group or individual who can affect or is affected by the achievement of the organisations objects' (Berginer et al 2012:831), which fits the categories defined by Khang and Moe (2008). This is the definition used in this research, even though the context is the demonstration of results rather than conflict or needs analysis. Table 1 is 
mapping information from the stakeholder analysis about the roles and interests of stakeholders to compare the three key stakeholder groups (Julian 2012). They are compared in relation to their contribution to achieving the results (what they bring to the project), with which other stakeholders they have primary contact, and the differences in how the particular stakeholder groups view and understand results. 


\begin{tabular}{|c|c|c|c|}
\hline $\begin{array}{l}\text { Description of the } \\
\text { stakeholder }\end{array}$ & $\begin{array}{l}\text { A thematic or } \\
\text { geographical group } \\
\text { who will experience the } \\
\text { actual results of the } \\
\text { intervention (positive or } \\
\text { negative, intended or } \\
\text { unintended, direct or } \\
\text { indirect). Usually a } \\
\text { small locally constituted } \\
\text { group or set of people } \\
\text { with shared } \\
\text { characteristics and an } \\
\text { interest in change at a } \\
\text { local level. }\end{array}$ & $\begin{array}{l}\text { A national NGO or } \\
\text { international NGO with } \\
\text { a local presence that } \\
\text { has systems and } \\
\text { structures for } \\
\text { fundraising and } \\
\text { managing several } \\
\text { projects/programmes at } \\
\text { once. }\end{array}$ & $\begin{array}{l}\text { Institutional donors, } \\
\text { government and } \\
\text { multilateral agencies, } \\
\text { and international } \\
\text { foundations. }\end{array}$ \\
\hline $\begin{array}{l}\text { Contribution to } \\
\text { achieving the project } \\
\text { results - what the } \\
\text { stakeholder brings to } \\
\text { the project }\end{array}$ & $\begin{array}{l}\text { Bring local expertise, } \\
\text { understanding of the } \\
\text { context, local continuity } \\
\text { and local resources. } \\
\text { Usually provide the } \\
\text { "effort" needed to make } \\
\text { changes to local } \\
\text { behaviour (outcomes) }\end{array}$ & $\begin{array}{l}\text { Bring funding, } \\
\text { technical, } \\
\text { administrative, planning } \\
\text { knowledge and skills, } \\
\text { and additional } \\
\text { resources. }\end{array}$ & $\begin{array}{l}\text { Bring money and } \\
\text { political links. }\end{array}$ \\
\hline Primary contact with & Implementing agency & $\begin{array}{l}\text { Both local partner and } \\
\text { the donors }\end{array}$ & Implementing agency. \\
\hline $\begin{array}{l}\text { Understanding and } \\
\text { view of results }\end{array}$ & $\begin{array}{l}\text { This group has the } \\
\text { highest interest in the } \\
\text { project "success" } \\
\text { because it will change } \\
\text { their situation for the } \\
\text { better. Beneficiaries } \\
\text { may see the results } \\
\text { within a wider context } \\
\text { but it is unlikely they } \\
\text { actively participate in a } \\
\text { larger programme. Only } \\
\text { the local people can } \\
\text { directly answer } \\
\text { questions about the } \\
\text { relevance to their } \\
\text { situation of the actual, } \\
\text { demonstrated and } \\
\text { reported results. } \\
\text { The key interest of this } \\
\text { group is the local level } \\
\text { results - including } \\
\text { results not included in } \\
\text { the formal reporting. } \\
\text { These "unintended, } \\
\text { positive" results may be } \\
\text { the most important (or } \\
\text { indeed the only) results } \\
\text { of value for this group. }\end{array}$ & $\begin{array}{l}\text { There are complex } \\
\text { relationships and power } \\
\text { dynamics within the } \\
\text { implementing agency } \\
\text { because the } \\
\text { perspectives vary from } \\
\text { the Board of Directors, } \\
\text { programme directors, } \\
\text { fundraising team, } \\
\text { learning officer and in- } \\
\text { country director. } \\
\text { The results will affect } \\
\text { the future of the } \\
\text { implementing agency } \\
\text { who are interested in } \\
\text { learning what can be } \\
\text { improved as well as } \\
\text { how the results fit with } \\
\text { the strategic plan. They } \\
\text { are concerned with } \\
\text { what gets published in } \\
\text { the evaluation report in } \\
\text { terms of success and } \\
\text { failure, and also seek } \\
\text { good practice for } \\
\text { learning and for future } \\
\text { strategy. "Unintended, } \\
\text { positive" results need to } \\
\text { be re-framed to show } \\
\text { added value by the } \\
\text { implementing } \\
\text { organsation. }\end{array}$ & $\begin{array}{l}\text { The donors want their } \\
\text { money used well (Zivik } \\
\text { 2007).Donors want the } \\
\text { evaluation to feed into } \\
\text { decision making (Aucin } \\
\text { 2005) and achieving } \\
\text { their political objectives } \\
\text { (for example DFID). } \\
\text { Donors focus on the } \\
\text { strategic importance } \\
\text { and possibly political } \\
\text { importance, and are not } \\
\text { usually concerned with } \\
\text { secondary project } \\
\text { impacts that are of } \\
\text { importance to local } \\
\text { beneficiaries, but are } \\
\text { outside their formal } \\
\text { strategy. Donor } \\
\text { reporting generally has } \\
\text { no place to include } \\
\text { such "unintended, } \\
\text { positive" results. }\end{array}$ \\
\hline
\end{tabular}


Table 1. Stakeholder groups and interest in results.

\section{Relationship change during the project cycle}

As a project evolves through its life cycle the relationships between the stakeholders evolve. Khang and Moe (2012:76) have a categorisation of four project stages of 'concept', 'design and planning', 'implementation', and 'close and evaluation'. This four-stage description is consistent with a range of project cycle materials (DFID Evaluation Guidelines (DFID 2009), Project Cycle Management (European Commission, 2002) and Results Based Management (CIDA, 1998)), and was used in this research as the basis through which we explore the stakeholder relationships and interests.

In the following description and analysis it assumes the same project example as described in the methodology, where there are local actors in the village, and implementing agency managing the funds, and an international project funder.

\section{Stage 1: Concept and project funding proposal}

(a) Key relationships.

The first stage of the project starts with the definition of a need, the identification of a possible solution, and then the preparation of a concept paper or funding proposal. At this stage, the beneficiaries and people who will carry out the project are highly involved, but those who provide the funding may not yet have a direct role (or indeed any knowledge of the future funding proposal). The key relationship for results at this stage is between the beneficiary group (for example a local village organisation wanting to establish a peace committee that needs external support and funds) and an implementing organisation (for example an INGO with a country office that can partner with the village organisation). Unless the beneficiaries and the implementing organisation work together, the first stage is unlikely to succeed. If the beneficiaries choose not to cooperate then the implementing organisation has no legitimate base on the ground and it can be argued that they should not proceed. Conversely, if the beneficiaries want the project but lose the support of the implementing organisation, then they are unlikely to be in a position to make an international funding request by themselves.

\section{(b) Activities and processes}

This first stage is primarily taken up with an internal process between local and international partners (such as developing a memorandum of understanding). All parties are keen to demonstrate competence to get results and make a difference. The important contribution to demonstrating results at this stage is analysis of the current situation and identifying the outcomes that an intervention could achieve. At this stage, the implementing agency may well be aware that the beneficiaries have outcomes that they are seeking, but which do not fit into the objectives of the funder. One role of the implementing agency is to act as a "gatekeeper," or funding proposal editor, to ensure an 
improved chance of funding success by re-formulating or removing local objectives that lie substantially outside the interests or strategy of the intended donor.

The end of this stage equates with project go/no-go in traditional project management (Wysocki 2014) - usually the implementing agency decides if the funding application should be presented to the donor, and then the funding decision is made by the donor instead of the recognised clients - the local partner and implementing agency. At this point the dilution of the "project client' role begins (Wysocki 2014, Daillo and Thuiller 2004). Thus, the dilution of the recognised and widely agreed client role, and the introduction of power imbalances regarding the decision to go ahead with a project starts early in the project cycle for International Development project management. This dilution can then be tracked over the life of the intervention.

\section{Stage 2: Project Design in detail and Planning}

(a) Key relationships.

In the second stage, detailed project design and planning, the funder now takes on a more prominent role in the project. A new challenge arises because the funder starts to require that results are demonstrated in the reporting in order to meet the donor's external priorities.

(b) Activities and processes

Monitoring and evaluation (M\&E) design is usually considered at this stage (Spurk 2008). Monitoring is the underlying process of reporting, and M\&E design requires an understanding of the complexity of the situation (Eoyang and Berkas (1998)) as well as identification of the specific staff who have the skills to collect, analyse and report the information. Other work at this stage includes defining job descriptions and specific activities and outputs, securing work permits, organising the logistical support, and similar tasks (APM 2006).

As the project starts to emerge into the real environment, the aims and planned outcomes may begin to be adapted, or more challenges emerge. The project starts to connect to other stakeholders and external events and local stakeholders find that some of their core outcomes may be relegated to the status of minor results of the overall programme with little place in the reporting. No project is an island (Engwall, 2003), but local partners may at this second stage find themselves being more "offshore" to the strategic results than they expected during the first phase.

\section{Stage 3: Implementation}

(a) Key relationships.

Local stakeholders will be focused on meeting targets for activities and outcomes: demonstrating the results will tend to be left to the comparatively few staff who specifically have monitoring and reporting in their role. The donor may require periodic activity reporting to ensure progress is made. The complex task of keeping the project on track may include periodic reviews involving all stakeholders and reporting interim results, and may inlcude 
regular evaluation though this is often left to half-way through the project or the end of the project.

As the situation changes it may be a challenge for the project to align the planned project outcomes (and therefore the impact contributing to strategic outcomes) with the actual outcomes. Local circumstances can mean planned and actual outcomes or impact begin to diverge at this stage. Reported results may start to diverge from actual results in order to address these conflicting needs.

\section{(b) Activities and processes}

This phase of the project is when the immediate changes take place, when the first results (immediate outcomes) are achieved and is key in terms of demonstrating results (Khang and Moe 2008). The longer term outcomes and the societal level impacts will usually be assumed on the basis of the Theory of Change, which will indicate if the project was making assumptions about expected resource, behavioural or attitudinal changes to achieve the goals (Church and Rogers 2006). The project plan may change, and the intended impact may be revised (for example if new information about the needs of the beneficiary groups becomes available, or the underlying circumstances are affected by external factors) or unintended consequences take place (these could be both positive and negative). In complex environments, projects rarely proceed exactly as planned.

\section{Stage 4: Close and evaluation}

Although the close of the project and the completion of the evaluation do not always coincide in time, they occur at similar points in the project and evaluation cycles.

At this final stage a mismatch between expected results and actual results is not unusual, and may require a review of the use of monitoring data, the type of data collected and the definition of the causal relationship between project activities and changes in the beneficiary community. Here the donors play their largest role by requiring that the intended results be reported in a format through which the benefits to their own strategic objectives are clear. The implementing agency has an interest as their future funding and reputation may be dependent on both the results and the reporting. The beneficiaries, for whom the project outcomes, and possibly the impact, have already taken place, and who do not have direct contact with the donor, hold much of the evidence of change (in terms of how their lives and communities have changed). This makes them important in the demonstration of results for the implementing agencies and donors, but with no other role than as the source of primary information for evaluation. This effectively removes their role as project client and the donors act as the de facto client taking credit for the reported results of the project. Evaluations are usually written to inform the donors, it is rare that evaluations are conducted to present results to the beneficiaries. 


\section{Exploring competing interests}

This research considers the following four influences on the competing stakeholder interests, the selection was based on the practitioner interviews conducted by the author: (i) individual mental models, (ii) the organisational systems within which they work, (iii) the nature of the relationships between them, and (iv) the methods used for collecting and reporting results.

\section{Individual mental models}

Understanding stakeholders' expectations is important in understanding results and how they are reported. Operational Research, although originally a mechanistic tool, suggests that everyone who looks at a problem has a 'mental model' (Forder, 2010; Jackson, 2003) which provides a 'lens' through which they view information. Mental models reflect people's preferred ways of working, values and cultural influences. Neufeldt (2008) argues that different values drive two categories of people 'circlers' and 'frameworkers', a way to differentiate individual approaches to project planning and implementing. Frameworkers tend to have an embedded trust that objective indicators can be used to collect data in a scientific manner and the collection of data does not in itself influence the situation. This supports the view that it is possible to plan for achieving intended outcomes. Circlers, on the other hand, see indicators and evaluation as subjective, selected by external actors whose decisions influence the situation that they are observing. Planning is seen as a process which will evolve as the project develops, without a fixed view of the exact outcomes and impact. Circlers focus on processes rather than outcomes.

If the stakeholder requiring results has a predominantly frameworker view, but the implementer approaches problems as mostly a circler, then the collection of data, the judgements made about what it is important to report, and even the presentation of data, will be based on different sets of assumptions and expectations. In this case the frameworker may not see clear 'demonstrated results' when presented with processes and stories.

Interviewees in this research reinforced the different mental models as a practical consideration. Two interviewees expressed clear positions about differences regarding expected results, suggesting that "[information] is interpreted differently by different people"(interviewee 1) and that " [ ... ] for people well trained in [using] log frames, and if their brain works that way, that's fine, but people consume information in different ways."(interviewee 2).

\section{Organisational political and cultural systems}

The project stakeholders sit within different organisational and cultural systems (where they work or live), and these produce conflicting interpretations of data. Boddy and Paton (2004) describe these conflicting views as structures which emphasise different goals or interpretation of the environment, and that the distribution of power creates a political system in which actors have different types and levels of power and see the project as serving different interests. The work of Boddy and Paton (2004) considers a project in an organisation, but in this research the same conflicts are considered in a larger complex environment of a peacebuilding project. 
These systems will influence the stakeholders to prioritise different aspects that are important to them, or select and report data according to culture or social expectations. The needs and expectations of the stakeholders cover a wide range (Julian 2012:219), from reporting on the strategic and national level thus requiring to be aligned with political goals and relevant to larger strategic interests, to the field level concern with what changed in a village. The tension created by different demands can influence whether results are accepted as valid and useful.

Different understanding of what constitutes useful results, what role those results play, and through which political-social power system they are being interpreted, influence the extent to which actual results are included as demonstrated results.Actors at the beneficiary level or implementing agency level may be frustrated because they are not able to understand why their greatest achievements are not recognised. This is not only a matter of communication, but, as Marshall says, "The focus is on indirect and normalised forms of power and control inscribed and internalised as specific rules and principles of appropriate conduct [ ... ] ". Marshall (2006).

Evaluation methods that manage the complexity and conflicts In Julian (2012), different evaluation methodologies were applied to a single project from the Nonviolent Peaceforce Sri Lanka project (Furnari 2010). This showed that changing the methodology led to different evaluation results. Project complexity (PMI 2013) can refer to the aspects of the projects itself such as many stakeholder, happening in a new place or using innovative approaches. It can also refer to the environment such as having many external factors to include, or taking place in a complex adaptive system. If a project is 'complex' then using a linear evaluation methodology will capture results in a limited manner. Different stakeholders may choose a different linear path simplification of the same complex situation, for example the expected outcomes (behaviour changes) resulting from a project activity may be different when considered at the village level (a direct impact on people's lives) and the strategic level (a small local change that will influence much larger political decisions). In this case the two linear paths may diverge after the activity and lead in different directions. Reporting will usually be constrained to following a single path and may ignore all other simplified views (Julian 2012).

Most International Development projects operate in an environment which can be considered a 'complex adaptive system' (Hendrik 2009), for which few currently used evaluation methods are suitable. Eoyang and Berkas observe:

"Most evaluation processes are based on performance against predicted goals. Increasingly institutions that are not able to provide such basic evaluative information may not continue to receive support from funders. Historically, evaluation programs were developed to work in organizations that were assumed to be closed, stable and predictable. And in many situations, linear, low dimension evaluation systems provided adequate data to represent organizational 
performance approximately. Such evaluation approaches were close enough to meet the needs of organizations and their supporters."

(Eoyang and Berkas, 1998:p1)

Eoyang and Berkas further note:

To be effective... an evaluation program must match the dynamics of the system to which it is applied."

(Eoyang and Berkas, 1998:p1)

In summary, over the life of the project the different stakeholder groups play different, competing and complex roles and have different interests in achieving and demonstrating results. In particular, the demonstration of results depends on social, cultural and political influences that emerge as both individual mental models and organisational systems, and how they interact with the evaluation methods.

The model in this paper continues to show the difficultly in International Development project management of identifying the role of the client, and this is relevant to the acceptance of results. Both Francis (2010) and Reich (2006) suggest that the beneficiaries in the local area should be the client and the project should be meeting their local needs, as well as strategic or national interests. The client is the one who says 'go/no go' (Wysocki 2014) at decision points, and the one to whom project and evaluation results are reported at the end before the project team is disbanded. The major funder frequently takes this role and is thus de facto the client for key decisions. This creates problems in terms of who controls the project, and in particular for the reporting of results: who is reporting what to whom? When the identity of the client is uncertain, is divided between different stakeholders, or changes throughout the course of the project, consideration of who the results are for cannot follow a simple (non-complex) linear model.

\section{Applying stakeholder group interests over the life of the project for the demonstration of results}

The static view of stakeholders considered above, shows evidence of competing interests and uncertainty about the 'client' role. However, the project is a dynamic environment and this is now explored over the changing project life cycle. Missionier and Loufrani-Fedida (2014) described this as a dynamic stakeholder analysis.

The diagrams below differ from a standard analysis showing stakeholder impact on the project by showing stakeholder influence on the demonstration of results. In the conceptual phase, for example, the donors would not have a significant influence on the success of the project in a standard analysis, but due to their political power and authority in defining strategic interests, donors would have some influence on the demonstration of results at this first stage.

The two components of the analysis are the stakeholders "attitude" towards the project, and their level of "influence". Attitude in this context means the likelihood that they will accept the results that are actually produced. A 
positive attitude suggests they are likely to accept the results, and a negative attitude that they will be more difficult to convince (positive to the right or negative to the left). The vertical axis represents the level of influence or impact, that their acceptance of the results has on the project (the highest influence to the top and no influence at the bottom). This influence could, for example, be due to providing data, or making key decisions. Figures 1-4, plotting 'influence' against 'attitude', provide an indication of where the main stakeholders lie in relation to one another and how this changes over the life of the project.

The top-left part of the graph in Figures 1-4 indicate the group of people who need the most planned engagement strategy if the actual results are to be accepted and used; those who have significant influence but also have the least positive attitude towards accepting the results of the project. Giving this group additional attention could mean, for example, giving them ongoing reports over the life of the project, or it could mean taking time to fully understand their interests and their misgivings. A deeper understanding of the type of power and influence they hold will be required in order to fully meet their needs, which are not static. The other stakeholders have to uncover not only who wants to know what, but who wants to know what and when.

Stage one

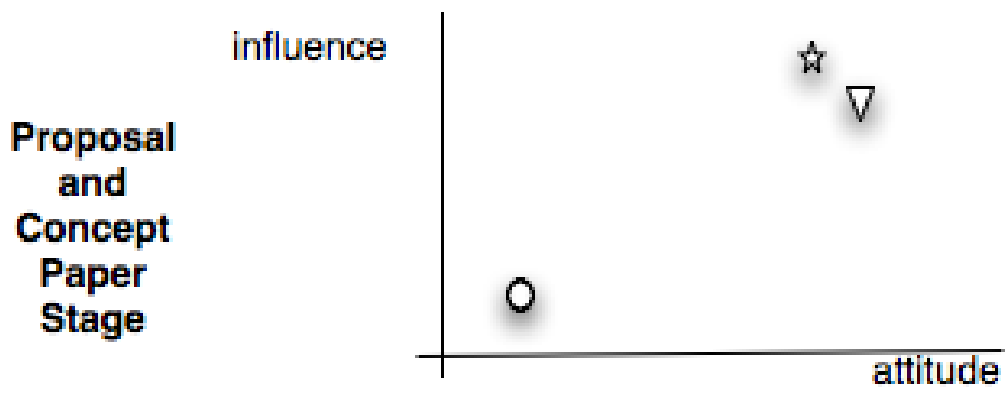

Large, often gov, donors

Implementing Organisation

$\nabla$ Local partner and beneficiary

Figure 1: Demonstration of results at proposal and concept paper stage

In figure 1, the donors can influence the way in which a project chooses it's focus to some degree, but both the implementing organisation and the beneficiary are highly influential and have a positive attitude to the project - at this stage they both consider that the project they design will achieve the desired results. 
Large, often governmental, donors will have limited involvement at this stage. They may have invited an application (or it may be that their funding opportunity has prompted the project discussion) and their interests will create the overarching environment within which international funders structure their conversations about projects.

The organisational expectations are that other stakeholders will fit their programmes without significant challenges, because their control of funding gives them over-riding power. Large donors will have a major strategic goal and a 'frameworker' perspective on how this can be achieved. An interviewee said that one aspect of the planning is to ensure "that project objectives match strategic objectives of the donor" (interviewee 9). As a donor, one interviewee said "We are more likely to fund projects with SMART objectives" (interviewee 4 ), an indication of the takeover of the client role by the donor at this stage.

Implementing organisations have a positive attitude towards their project because they can see both the need and how they can contribute, and will see the strategic contribution of the project. Their influence is high because they provide the access channel to donor money and will probably write the proposal. Politically, although they are focused on what is happening locally, they are also concerned about the internal values and pressures of their own organisation and they way they are viewed by large donors. This means that they may rule out some potential projects on non-technical grounds. The key organisational expectation is that they need to fit local concerns to a wider strategic goal. The intention is to meet both the local need and the funder's criteria - it is in the implementing agency that the gap between these is negotiated.

International implementing agencies include both frameworkers and circlers the organisation structure has to interface the circular view from the local partners and beneficiaries and the frameworker view from the donors. In the interviews it was recognised that donors liked linked projects to be grouped together; they did not want results from only one project because one single project cannot achieve the donor's strategic goals. One interviewee said "donors want a package of projects...there is a benefit in collaboration" (interviewee 5).

Local partners and beneficiaries have a positive attitude to demonstrating results because they want to see results and their influence is high because they have access to the data about the situation and the intended change. The frameworker approach thinks in terms of projects and defined timescales. Local beneficiairies rarely think in projects, but rather in overall desired change to their lives; this is close to the circler way of thinking and focuses on the local changes that can be achieved. The primary relationship of the beneficiaires in terms of how any achieved results will be demonstrated is with the implementing agency

In this stage the key relationships are between the local beneficiaries and the implementing agency for building trust and communication mechanisms, and within the implementing agency between the country focused team work and 
the functional area of fundraising (these roles are usually split because they need different expertise and skills). Evaluation methodology is rarely considered at this stage.

Stage two

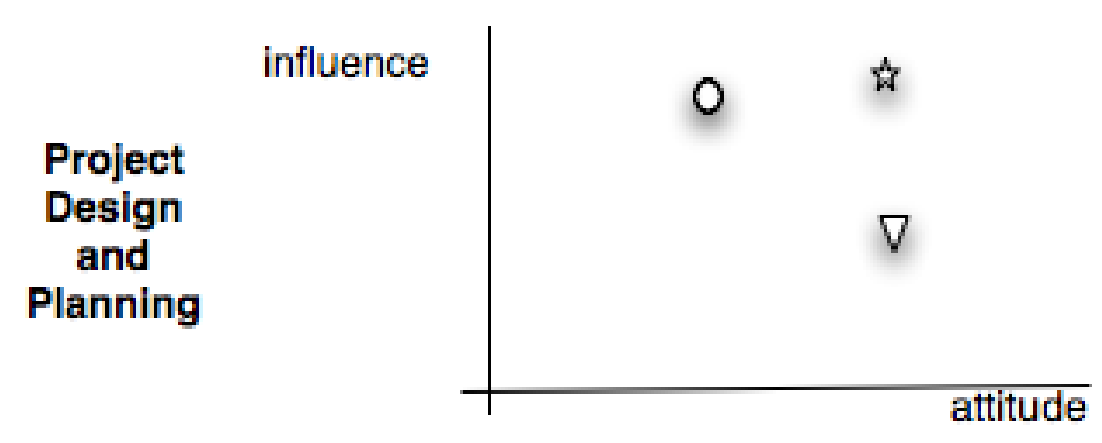

\section{Large, often gov, donors \\ \& Implementing Organisation \\ Local partner and beneficiary}

Figure 2. Demonstration of results during project design and planning

In Figure 2, after funding has been secured, the donors have moved to being more positive about the project, it is now part of their overall portfolio and they have an investment in its success, but it is unlikely that they will be as convinced as the local partner and implementing agency who have a greater degree of ownership, especially of the detailed implementation. The donor influence is now much higher because they control the financial resources that will enable the project to continue, which means that incorporating their desired evaluation and reporting approaches and strategic objectives are given a high priority by other stakeholders. The local beneficiaries or partner have less influence at this stage because many of the processes in planning involve meeting the funders requirements and deciding how the local agency will be involved.

Large, often governmental, donors have considerable influence because they control money and can make demands about results and evaluation. They probably take a neutral attitude on demonstrating results because although they fund the project they will be expecting "the project" to demonstrate its own results. Whether this means the implementing partner generates reporting, or the local beneficiaries are also involved may not be of as much interest as ensuring that the reporting demonstrates that money has been well spent and larger strategic goals achieved (and possibly political interests satisfied). This is a frameworker approach. The project that was funded will 
have competed with other unsuccessful projects for the funding, and therefore the funder has an expectation that it will provide results contributing to their strategic goals.

Implementing organisations also have a strong influence at this stage because they have access to evaluation and reporting resources and have experience and knowledge from past projects. They will have the opportunity to make implementation decisions about the evaluation and evaluators, including data collection. The implementing partner is likely to be the key stakeholder in defining and planning monitoring and evaluation. Their attitude is buoyant because they have an interest in demonstrating good results and some understanding of what is required by funders. In this stage the frameworker view dominates as agreements, contracts, logistics and scheduling takes place, fitting the project into a frameworker view, including the planning evaluation approach and timeline. Within the implementing organisation, now funding has been secured, the key relationship is between the country focused team and the functional areas related to purchasing and contracts. People from these teams have to relate to one another but they probably have different mental models of success - one being based on efficiency and outputs and the other on a wider range of outcomes over a longer period of time.

Local partners and beneficiaries will also have a strong influence if they are participating, for example, in workshops to define evaluation indicators locally. This participation depends on the implementing partner who has significant power at this stage. Local partner attitude is positive because they want to see all the changes proposed by the project come to fruition (and would expect to be able to show them and contribute to reporting).

The key relationship is now a contract between donor and implementing agency, and possible Memorandum of Understanding (MoU) between implementing agency and local partner, which dictates the scope and limits of the planning framework, and the expected results. The frameworker approach is clearly dominant.

Stage three 


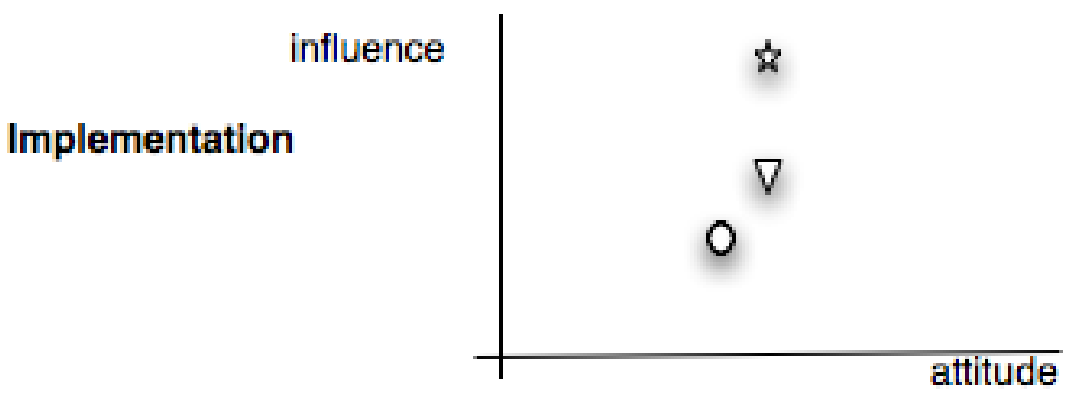

\section{Large, often gov, donors \\ मे Implementing Organisation \\ $\nabla$ Local partner and beneficiary}

Figure 3. Demonstration of results during implementation.

In Figure 3, as the project has to adapt to external challenges and the inevitable changes to the plan, and conflicts between the local beneficiaries and implementing agency emerge, both local actors and implementing agencies are likely to find their wholehearted support for the project to be disrupted, especially if there are conflicting interests over changes in priority or direction of the project.

The implementing agency, in controlling the financial resources and being effectively the gatekeeper for access to the donor, have the biggest influence at this stage. The way they use the resources under their control will impact on the actual results achieved, and the type or volume of data and information collected for demonstrating and reporting the results. Having allocated the funding, the donors may require interim reports in a standardised format (the frameworker approach) but do not otherwise influence how the funds are spent and therefore have limited influence on the results. The local beneficiaries clearly remain influential to the extent that without their involvement there will be no project or results, and therefore ensuring the project meets their needs to produce results which help them is essential.

Large, often governmental, donors are not involved in the actual implementation of the project and therefore have little influence at this stage on demonstrating results. This accounts for their low position on the influence scale. Any interim reports required are likely to focus on how much progress has been made by the project in contributing to their strategic goals, a frameworker approach. This may be the first time that the data collected in the project demonstrates results to the satisfaction of the donor (or not).

Implementing organisations remain influential because they will be delivering interim reports to donors and are therefore in a position to control the data and decide what the donors should hear and in what report format. Their 
influence is derived from control of the process from collecting data and making analytical choices, producing reports and managing the monitoring and evaluation activities. They continue to need to manage the relationship within the organisation between those working at a local level who can see the results, changes and challenges that the project is facing, which may mean they see unintended results, and those who want to collect data on the original intended goals as part of the contract of receiving funding.

Local partners and beneficiaries exert influence because they hold much of the data and need to be involved in interviews or workshops in order to demonstrate results. They may have a neutral or even negative attitude if they are asked to complete too many forms or are subjected to multiple interviews, or feel that their views are not being listened to or fairly reported. Their interest is in seeing the changes rather than convincing the large donors. They are not often the decision-makers in demonstrating results. The local beneficiaries continue to be forced to share the project client role with the donors, because the project client is usually the one who requires the actual change, who will benefit from the project being successful.

The key relationship remains that between implementing agency and local partner, and it is through this relationship that actual results are delivered.

Stage four.

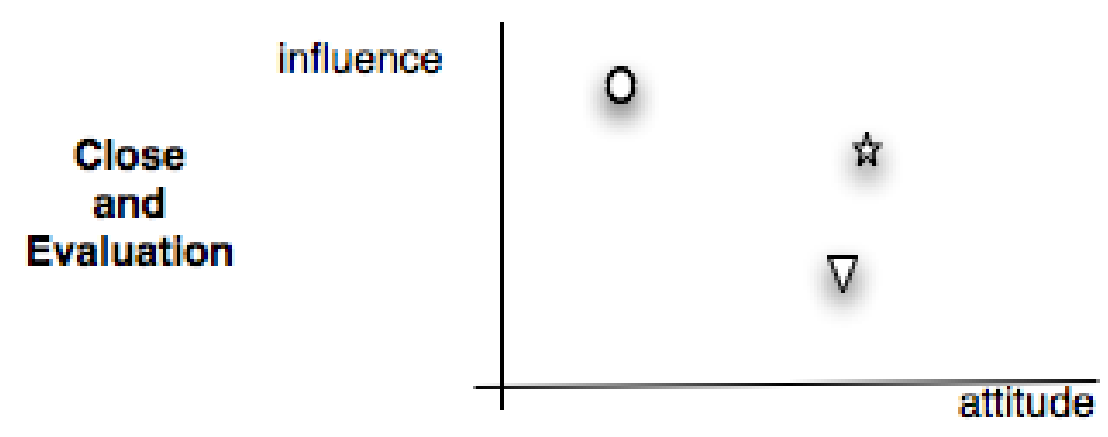

- Large, often gov, donors

मे Implementing Organisation

$\nabla$ Local partner and beneficiary

Figure 4. Demonstration of results at close and evaluation

In Figure 4 the donors will receive a final evaluation report and make a decision on the extent to which they believe the project has been successful, and what strategic learning can be expected from the results. This will 
influence the future relationship of the donor with the implementing agency and maybe also the local partner. This makes the donor very influential but without being necessarily convinced of the success of the project. If the project has achieved results then local beneficiaries usually remain supportive of the project, but do not have much influence on what results are produced and reported from the data collected in monitoring; the analysis takes place within the implementing agency structure after the data is handed over. The implementing agency remains both positive towards the project and influential because they control the results data and are most likely to appoint the external or internal evaluator.

Large, often government, donors have a strong influence at this point because they may withhold final payment if acceptable reports are not submitted, or they may decide to commit to future funding for the project if the reporting presents a "success story" that fits their frameworker approach. The funder can therefore make significant demands about evaluation approaches, external evaluation and scope of the evaluation. If interim reports have not provided the expected results, then there will be a more negative attitude. This places them in the most critical quadrant of the stakeholder analysis. Stakeholders who are very influential, but have a negative attitude can have a significant overall negative impact on the project if their needs (explicit or unstated) are not met. Because this negative attitude relates to demonstrating results, there could also be a negative impact on future projects.

One reason for donors adopting the frameworker perspective (Neufeldt 2008, Julian 2012) is that frameworkers expect that learning from one situation can be transferred to another. This is important for major donors who may use evidence from results to influence policy decisions and will usually assume that experience can be transferred and replicated.

During interviews there was some recognition that the donors have specific needs in terms of results, such as needing something which we "might think of as concrete results" (interviewee 1) and that "Donors like to stick to the Logical Framework and they can understand the projects, but they are not happy with the reporting and the results." (Interviewee 2).

The interviewees acknowledged that there were challenges. "The challenge is evaluating and demonstrating how those projects have made a difference, so it's difficult in a traditional manner to map those out."(Interview 3). There was some benefit from using the logical framework as a reporting structure; "the log frame DOES have a value. It creates a structure for the projects something that needs to be followed. It gives a good direction. In the end it's okay to work with the log frame." (interview 2). However, interviewees also wanted donors to explain more about what they were looking for. "There needs to be more in-country training and outreach by donors to explain what they're looking for." (Interviewee 4).

Implementing organisations also have a strong influence at this stage because they collect, analyse, format, edit and transmit the data about the results. They will manage the evaluation programme and activities and 
arrange the work of an external evaluator. They can influence the results at this stage by deciding on the details of the evaluation methodology, even if the overall direction is set by the donor. For example the implementing partner can propose an evaluation method that recognizes the complexity of the situation or select an evaluator they consider has a particular understanding of the context.

The implementing organisation has a positive attitude because they want and expect the reporting of the results to be accepted, leading to future funding, and also laying down lessons to be learned for the future. They therefore have an incentive to make every effort to demonstrate the results they have produced.

Local partners and beneficiaries have the data about the changes and outcomes of the project, but little influence on evaluation methods or what happens to the data they provide. They have a neutral attitude to demonstrating results because they have no influence and can see little to gain directly from providing the data. The outcomes are part of their lives, how the outcomes are reported to a distant donor may only be of interest in the context of possible future funding.

The focus of energy on relationships may now change to ensure that the evaluation for the donor is carried out according to their needs, and whilst the relationship between local partner and implementing agency continues, the local partner become a source of data for the evaluation or discussion about the sustainability of the project.

In the evaluation stage stakeholders are differentiated not only by their expectation of the results, but also by the contribution that they make. Local participants may be essential to the process of providing information for the evaluation they have less influence than the other stakeholders in how this information is used to generate a report that addresses the needs of the donor.

\section{Discussion.}

Stakeholder interests and the systems in which they work The approach used for stakeholder analysis distinguishes between the needs and motives of the different groups who want to see the results of interest to them. Individual stakeholders are positioned in the matrix of demands and interests, which shows (a) where the existing challenges lie and (b) why they occur at different times over the life of the project.

\section{Donor influence.}

Donors have significant influence at the early stages of a project when funding is being arranged. This is the time when the expected outcomes are defined for the project and to increase the chances of a successful proposal, other stakeholders will frame their outcomes in terms of the donor's strategic requirements. Once a project is agreed the donors do not have as much influence during the implementation phase and only return to being highly influential at the final evaluation stage. By this time many internal and external changes are likely to have taken place, some of them outside the control of 
the project. The actual outcomes will not be a perfect match for the expected outcomes. Even if the actual outcomes are useful, or fulfil the expectations of other stakeholders, the donor may not be able to accept as results any outcomes other than the planned and expected ones.

At the close and evaluation stage, the large donors are in the top left hand corner of the diagram (Figure 4), which is typically the location of the stakeholders who are the most demanding and most influential. They are constrained to show success according to the planned and expected outcomes, and are in a position to insist that project reporting reflects this success. They are very influential because of their role in supplying potential future funding, but if their previous experience (either from interim reports or more broadly in the sector) is that results are often not successfully demonstrated, then they will likely have a negative attitude. Thus it follows that, in producing and demonstrating results, other stakeholders must pay attention to the needs and constraints of reporting expected results to the donors.

\section{Implementing agency influence}

The implementing agency has multiple, often conflicting, roles. Where donor and local beneficiary interests do not fully coincide they need to ensure as much overlap as possible, and at the same time need to meet their own success criteria, keep an objective view of progress, and also 'get things done'.

As implementing agencies hold the primary project management and evaluation roles, and it is shown that they connect with all stakeholders, they play a particularly important role in weaving together the complex relationships and interests. Implementers are in a position to design evaluation processes that acknowledge the complexity of demonstrating results. Whilst their influence is generally high, their organisational culture will mean there are tensions inside the agency as it attempts to connect the interests and needs of both donors and local beneficiaries. This role may well depend on political alliances and the ability to understand and interpret positions that reflect different cultures and mental maps.

\section{Local beneficiary influence.}

Local partners and beneficiary groups often do not exercise much decisionmaking power or manage much of the resources. They do, however, hold the keys to most of the first-hand data and are crucial to delivering impact. This makes them influential, but in a different way from those who provide the funding. While beneficiary groups should play an important role in the design and implementation of any evaluation. If the donor supports an evaluation approach that does not include the views of local partners or beneficiaries (e.g. through interviews), then their level of influence is reduced. While local partners have more influence at the start of the project, the contested nature of their 'client' role means that their influence on demonstrated results may decline.

The different mental models 
Using the concept of mental models can help show how different expectations shape our plans to collect and analyse data. Donors are predominantly framework type organisations and require results to contribute to their strategic aims. The dominant mental model of what project results should look like will fit a goal based evaluation using the planned objectives. This will run from the conceptual design phase at the start through to the close of the project if the donors have the most significant 'client' role in the project. The local beneficiaries, trying to solve the real problems they face on the ground and overcoming the challenges which disrupt any project plans, are more likely to think as circlers. Beneficiaries receive training on fitting into the frameworker style, and this may be the individual style of some local participants, but their mental model of results means that they see actual results as the changes in their lives, not the pre-planned outcomes. These changes may be based in physical reality and readily measurable (e.g. access to services) or may be entirely perceptual (e.g. sense of security). How much local beneficiaries they are the true 'client', especially if the benefits they experience are not listed as formal project objectives is unclear - although in the standard model beneficiaries are the people who every project actor says they are trying to help.

In this analysis, the implementing agency is the connection between stakeholder groups with different mental models, and must find a way to translate plans and results to stakeholders with very different understanding of results.

The influence of organisational cultures and systems.

Analysis of the systems within which donors and implementing organisations exist is made easier because they both directly relate to the dominant international political and cultural system. This system normalises hierarchy, neoliberal competition, and the central role of the state. Power and prestige is given to those who fit a managerial model of planning and results (for example Project Cycle Management (European Commission 2002)) by rewarding them with more funding and a higher profile in policy work. There is significant coercive power in having to either fit into the Logical Framework or not receive significant institutional funding. Very local projects who do not fit this dominant culture (indeed they may be seeking to change local power structures), need an implementing agency to be able to translate their needs into a language and model that will show how the strategic interests of donors will be met, and which also enables the implementing organisation to meet it's own needs to continue, grow and compete with other implementing organisations.

How do the stakeholders relate.

The key finding from the analysis is the importance of the implementing agency in supporting the communication between local partner and large donor. The position of the implementing organisation on the influence/attitude diagram is surprisingly stable throughout the project cycle and varies less than the other partners.

\section{Methods used summary}


The purpose and design of any evaluation strongly influence the reporting. If the evaluation purpose is to demonstrate that the donor's original strategy was successful (or not) from the perspective of the donor, then there may be no opportunity to include results that are of local importance. If the local beneficiaries are not perceived as the key client, and in the context of the greater influence of donors compared with local partners in the last phase of the project, the need for broad evaluation that captures the actual impact may not be understood. The consequence is that important but unintended positive outcomes may be lost.

\section{Conclusion}

This paper presented an analysis of the impact of competing stakeholder interests on the challenge of demonstrating results in complex International Development projects, and to evaluate how it changed over the life of the project.

A difference between actual results achieved and demonstrated results is in part due to the stakeholder groups who have very different expectations. The local beneficiaries see actual change, in its complexity, and do not require results to fit into a larger strategic or political framework. The donors expect results to contribute to their large strategic objectives, but have very little direct contact with the local beneficiary group. They understand results to be those analysed and collected by the implementing agency and the evaluation team. The implementing agency has internal competing interests between field staff, managers and directors, all of whom will have their own mental models about results.

If we acknowledge that mental models, culture, social structures and politics affect the acceptance of demonstrated results by some stakeholders and not by others, then we must also discuss where the responsibility lies for communicating across these divides and include power and politics in our project management and evaluation work. The relative power of each stakeholder group will impact the priority given to their needs, suggesting a rationale for why donor interests have more influence in demonstrating results than local partners. However where there is power there will also be resistance (Lukes 2004) to the dominance of that power, for example this could manifest itself inside an implementing agency as field staff or learning officers attempt to use evaluation methods that show unintended consequences, or even failure, as part of the learning process.

Along with recognition of the complex and dynamic nature of stakeholder roles over the project life cycle, the uncertainty about who is the real client - is it the local people or the donors - means we should question the way we distinguish between achieved results and demonstrated results. Within an overall political system which gives the donor the role of client (rather than those for whom the actual results are achieved), this gives power to the donor within the project and does not relate to the needs of the local beneficiary group. Rather than only focus on donor accountability, asking all project staff to take a more complex view of the relationship between the key stakeholder groups would be a transformative change. This change would be reinforced if 
the needs of the local beneficiary group were to be recognised as the true client, and other stakeholders would accept this so the recognition of results by the client would be the definitive acceptance. This would fundamentally change the power of donors in the current model and challenge evaluation to meet the needs of local beneficiaries rather than governmental donors.

Part of the reason why there is a gap between achieved results and demonstrated results is because actual results happen in a local environment, but the demonstration of them is about meeting demands of a politicised and powerful organisational system which is interested in meeting its own needs. This is a complex relationship because, although the power appears to rest with the donors, they cannot have their needs met without the successful project work at the local level and an actual change being achieved. This continuing dynamic, fluid interaction explains why demonstrating results in International Development projects is inevitably complex and requires further investigation.

Overall, this paper suggests that to close the gap between results achieved and results as demonstrated we need to understand the impact of individual mental models and organisational cultures in contributing to the complexity and dynamic changes over the life of the project, and not rely on a technical approach of changes procedures to resolve the competing interests among the stakeholders.

\section{References}

ACT Development (2008) A guide to assessing our contribution to change. ACT Development Stuttgart, Germany.

ALNAP (2009) ALNAP $8^{\text {th }}$ Review of Humanitarian Action: Performance, Impact and Innovation. ODI, London.

Anderson, M. B. (2004) Experiences with Impact Assessment: Can we know what Good we do? [Internet] Berghof Research Center for Constructive Conflict Management / Online Berghof Handbook for Conflict Transformation. Available from: $<$ www.berghof-handbook.net $>$ [Accessed on $13^{\text {th }}$ August 2009].

Association of Project Management (2006) Body of Knowledge $5^{\text {th }}$ edition. Association of Project Management.

Aucin, P. (2005) Decision-Making in Government: The role of Program Evaluation. [Internet] Available from: $<$ http://www.tbs-sct.gc.ca/cee/toolsoutils/aucoin-eng.asp $>$ [Accessed on June 8 $^{\text {th }}$ 2011].

Berginer, C, Jonas, D, and Kock, A (2012) Behviour of internal stakeholders in project portfolio management and its impact on success. International Journal of Project Mangement. Vol. 31 pp 830-846 
Broddy, D and Patton, R (2004) Responding to competing narratives. International Journal of Project Management. Vol. 22 pp 225-233.

Canadian International Development Agency (CIDA) (1998). Results-based Management in CIDA: An Introductory Guide to the Concepts and Principles. Ottawa, Canada.

Church, C and Shouldice, J. (2002) The Evaluation of Conflict Resolution Interventions, Framing the state of play INCORE International Conflict Research.

Church, C and Shouldice, J. (2003) The Evaluation of Conflict Resolution Interventions, Part II: Emerging Practice and Theory. INCORE International Conflict Research.

Church, C. and Rogers, M., (2006) DESIGNING FOR RESULTS: Integrating Monitoring and Evaluation in Conflict Transformation Programs. SFCG, Washington.

Crawford, P., and Bryce, P., (2003). Project monitoring and evaluation: a method for enhancing the efficiency and effectiveness of aid project implementation. International Journal of Project Management 21 (5), 363373.

Cropper, J. (2009) Project Management in International NGOs: a crossroads [Internet] Keynote speech at PM4NGOs Summit. Available from: $<$ http://ngolearning.org/pm4ngos/summit/default.aspx $>$ [Accessed on $3^{\text {rd }}$ October 2009].

Daillo, A. and Thuillier, D. (2004) The success of international development projects trust and communication: An African perspective. The International Journal of Project Management 23 237-252.

DFID (2009) BUILDING THE EVIDENCE TO REDUCE POVERTY: The UK'S policy on evaluation for international development. Department for International Development (DFID), London.

Engwall, M (2003) No project is an island: linking projects to history and context. Research Policy Volume 32, Issue 5, May 2003, Pages 789-808

Eoyang, G. and Berkas, T. (1998) Evaluation in a Complex Adaptive System. HSD Institute, USA.

European Commission (2002) Project Cycle Management European Union, Brussels.

Forder, R. (2010) Conflict Transformation: an Operational Research Perspective. In: Proceedings of the IMA $4^{\text {th }}$ Conference on the Analysis of Conflict Transformation. Oxford, IMA. 
Francis, D. (2010) Peacebuilding and Pacification. Pluto. London.

Furnari, E (2006) The Nonviolent Peaceforce in Sri Lanka. Impacts,Learning and Summary Paper August 2003 to December 2005. Internal document Nonviolent Peaceforce.

Furnari, E (2010) NPSL Valaichenai Team. In: Proceedings of the IMA $4^{\text {th }}$ Conference on the Analysis of Conflict Transformation. Oxford, IMA.

Goodhand, J., Vaux, T., and Walker, R., (2002), Conducting Conflict Assessments: Guidance Notes. Department for International Development, London.

Hermano, V., Lopez-Paredes, A., Martin-Cruz, N., and Pajares, J. (2013) How to manage international development (ID) projects successfully. Is the PMD Pro1 GUie going to the right direction. International Journal of Project Management 31/1 (2013) 22-30

Hendrick, D. (2009) Complexity Theory and Conflict Transformation: An Exploration of Potential and Implications University of Bradford, Bradford.

Hodgson, D and Cicmil, S (2006) Making Projects Critical. Palgrave Macmillan

Ika, L (2012) Project Management for Development in Africa: Why Projects Are Failing and What Can Be Done About It. Project Management Journal Vol 43 No.4 27-41

International Alert (2009) Making an Impact 2008. International Alert.

International Labour Organisation (2010) Project design Manual. Geneva

Jackson, M. (2003) Systems Thinking: Creative Holism for Managers Wiley and Sons, Chichester, England.

Julian (2012) Demonstrating Results in Conflict Transformation at Civil Society Level. PhD thesis. Leeds Metropolitan University.

Khang, D.B, and Moe, T.L. (2008) Success Criteria and Factors for International Development Projects: A Life-cycle-Based Framework. Project Management Journal Vol 39. No.1 72-84

LMU (2005) Project Management Certificate Training materials. Centre for Project Management, LMU.

Lukes, S. (2004) Power: A Radical view Pub: Palgrave.

Marshall, N (2006) Understanding power in project settings. In Hodgson and Cicmil (2006) Making Projects critical. Palgrave Macmillan p219 
Missonier, S. and Loufrani-Fedida, S. (2014) "Stakeholder analysis and engagement in projects: From stakeholder relational perspective to stakeholder relational ontology" International Journal of Project Management 32 (2014) 1108-1122.

Neufeldt, R. (2008) Circling and Framing Peacebuilding Projects Published in New Routes 3/2008 Peacebuilding Evaluation pp15-18 Life and Peace Institute, Uppsala.

Nonviolent Peaceforce (n.d.) What we Do: Sri Lanka. Available online http://www.nonviolentpeaceforce.org/what-we-do/past-operations/sri-lanka

ODA (1995) Guidelines on Stakeholder Analysis. Available online http://www.sswm.info/sites/default/files/reference attachments/ODA\%201995 \%20Guidance\%20Note\%20on\%20how\%20to\%20do\%20a\%20Stakeholder\% 20Analysis.pdf

OECD-DAC. (2008) Guidance on evaluating conflict prevention and peacebuilding activities OECD, Paris.

Paffenholz, T (2004) Designing Transformation and Intervention Processes. [Internet], Berghof Centre. Available from: < http://www.berghofhandbook.net/documents/publications/paffenholz_handbook.pdf $>$ [Accessed on August $17^{\text {th }}$ 2011].

PMI (2013) Navigating Complexity. Project Management Institute.

Project Management Hut (n.d.) What is Stakeholder Analysis? Available online http://www.pmhut.com/what-is-stakeholder-analysis (Accessed on June 8th 2011)

Reich, H. (2006) Local Ownership in Conflict Transformation Projects [Internet] Berghof Research Center for Constructive Conflict Management, Berlin Available at < http://www.berghofconflictresearch.org/documents/publications/boc27e.pdf $>$ [Accessed on August 17 ${ }^{\text {th }}$ 2011]

Schweitzer, C (2012) Nine years of Nonviolent Peaceforce in Sri Lanka. Available online < http://www.nonviolentpeaceforce.org/images/focus srilanka/9yearsNPSLImplementing\%20UCP-final.pdf $>$ Accessed December $4^{\text {th }} 2015$

Scriven, Michael (1991) Evaluation Thesaurus Fourth edition SAGE.

Spurk, C. (2008) Forget impact: concentrate on measuring outcomes. New Routes: Peacebuilding Evaluation 3/2008 Life and Peace Institute, Uppsala.

UNDP (2011) Programmes and Projects. Available online http://www.undp.org/content/dam/undp/library/corporate/Programme\%20and 
\%20Operations\%20Policies\%20and\%20Procedures/Programmes-andProjects-20-Nov-2011.pdf

Wang, W., Liu, W, and Mingers, J. (2015) A systemic method for organisational stakeholder identification and analysis using Soft Systems Methodology (SSM). European Journl of Operational Research 246 pp 562574

Wysocki, R . (2014) Effective Complex Project Management An Adaptive Agile Framework for Delivering Business Value. J.Ross Publishing

Zivik (2007) Monitoring of effects ( movie) Effects-oriented planning and implementation of projects working to promote peace - a manual. Institut für Auslandsbeziehungen e. V. (ifa), Berlin. 